\title{
Percepção de Mudança Organizacional: um Estudo em uma Organização Pública Brasileira
}

\author{
Elaine Rabelo Neiva \\ Maria das Graças Torres da Paz
}

\section{RESUMO}

Sendo a mudança organizacional um imperativo para as organizações na atualidade e tendo sua avaliação uma conotação muito complexa, o presente estudo objetivou avaliar a percepção de mudança organizacional conseqüente a um programa de mudança implantado. Foram os objetivos específicos: a) mensurar características organizacionais - valores organizacionais e configurações de poder - antes e depois de intervenções realizadas em uma organização pública brasileira; b) investigar a capacidade organizacional para a mudança e atitudes em relação à mudança, após as intervenções realizadas; c) investigar as mudanças individuais e organizacionais percebidas após a realização das intervenções. A aplicação dos instrumentos foi realizada antes e depois da implantação do referido programa, em dois momentos durante o período de quatro anos. Segundo dados encontrados, houve percepção de que a organização passou por mudanças na sua imagem externa, nos seus resultados e no desenvolvimento da competência profissional dos seus membros, mesmo havendo percepção de que a organização tem baixa capacidade para as mudanças. Os dados ainda revelaram que as atitudes dos indivíduos em relação à mudança foram de aceitação, mas também de temor. As características culturais da organização se mantiveram estáveis.

Palavras-chave: mudança organizacional; avaliação da mudança; características organizacionais.

\begin{abstract}
The organizational changes have been pointed out to be an imperative to the organizations nowadays, but its evaluation has been very complicated. The present study has the following objectives: a)measure organizational characteristics- organizational values and power considerations- before and after interventions accomplished in a Brazilian and public organization; investigate the organizational capacity for changes and attitudes towards the changes realized after the execution of interventions; investigate the individual and organizational changes realized after the interventions take place. The application of instruments has been carried out in two moments during a period of four years. According to data found, the organization passed through changes in its external image, in its outcomes and in its member's professional competence development. The organization showed low capacity for changes and individual preponderance attitudes were accepted and feared when related to the changes. The cultural organizational characteristics such as organizational values and power relationships were kept stable.
\end{abstract}

Key words: organizational change; change evaluation; organizational characteristics. 


\section{INTRODUÇÃO}

Os autores que publicam estudos sobre mudança organizacional comentam a velocidade fantástica das mudanças sociais, econômicas, políticas e tecnológicas e como as organizações precisam adaptar-se para fazer frente a essas mudanças (Tienari \& Tainio, 1999).

Apesar do imperativo dos autores, muito pouco é sabido, do ponto de vista científico, sobre o processo de mudança organizacional. O problema inicial diz respeito ao conceito. Muitos são os aspectos a considerar na definição do conceito: escopo, intensidade, tempo de reação, pessoas envolvidas, etc. Neiva (2004) apresenta o seguinte conceito de mudança organizacional:

Qualquer alteração, planejada ou não, em componentes que caracterizam a organização como um todo - finalidade básica, pessoas, trabalho, estrutura formal, cultura, relação da organização com o ambiente -, decorrente de fatores internos e/ou externos à organização, que traz alguma consequiência, positiva ou negativa, para os resultados organizacionais ou para sua sobrevivência (p. 23).

Junto aos problemas de definição, estão ainda dificuldades relativas à tipologia de mudança, considerando que sempre há necessidade de especificar qual tipo de mudança está sendo mencionada e qual é o objeto ou conteúdo da mudança (Lima \& Bressan, 2003; Neiva, 2003, 2004). Existem várias classificações sobre tipo de mudanças que ocorrem em organizações e, segundo Lima e Bressan (2003), tal fato está relacionado aos modelos que explicam o processo de mudança organizacional.

Os principais modelos explicativos de mudança seriam o modelo de Burke e Litwin (1992) e o modelo de Greenwood e Hinings (1996). O primeiro modelo estabelece conteúdos de mudança e o segundo tenta explicar o processo de mudança a partir de interações com o ambiente.

O modelo de Burke e Litwin (1992), por exemplo, afirma que mudança transformacional ocorre na organização, quando a cultura ou a missão organizacionais mudam. As demais características organizacionais seriam indicadoras de mudança transacional, ou seja, uma mudança de menor espectro na organização, o que nos remete à conclusão de que o conceito de cultura organizacional é preponderante na compreensão da mudança organizacional. 
Em resumo, o modelo dos autores classifica os processos de mudança organizacional a partir da identificação do conteúdo da mudança organizacional, estabelecendo assim características do sistema organizacional e teorizando um modo de funcionamento desse sistema. A partir de modelos, torna-se possível a avaliação da mudança, na medida em que os conteúdos teorizados podem ser alvo de investigação em momentos diferenciados. Outra possibilidade de avaliação da mudança seria mensurar o que os indivíduos percebem ter mudado na organização.

Outro modelo explicativo do processo de mudança organizacional, apesar de não postular conteúdos de mudança, é o de Greenwood e Hinings (1996). Esses autores se interessam mais por explicar o processo de mudança nas organizações. O modelo estabelece que a insatisfação dos interesses individuais e o grau em que os indivíduos se comprometem com os valores organizacionais funcionam como precipitadores da mudança e enfatiza também que as organizações são arenas nas quais coalizões, com diferentes interesses, graus diferenciados de envolvimento com os valores preponderantes na organização e capacidades de influenciar, tentam dominar. A pressão para mudança existe na medida em que grupos estão insatisfeitos com o grau em que seus interesses estão sendo realizados nas organizações.

Esses modelos, postulados anteriormente, traçam diretrizes gerais para a pesquisa de avaliação da mudança organizacional, porque, segundo Neiva (2003), é necessário fundamentar teoricamente para realizar tal pesquisa nas organizações. Como esses modelos apresentam problemas com a definição dos principais conceitos abordados, as autoras da presente pesquisa partiram de referenciais mais testados empiricamente para testar as relações e os componentes dos sistemas organizacionais preconizados pelos modelos.

Como mecanismos precipitadores de mudança, foram ressaltados por Greenwood e Hinings (1996) os conceitos de envolvimento com valores organizacionais e insatisfação de interesses. Além disso, os autores ressaltam o fenômeno da política como fundamental para a introdução de mudanças nas organizações.

Como componente do sistema organizacional, para Paz e Tamayo (2004), cultura é a forma de pensar, agir e sentir compartilhadas nas organizações.Os autores propõem um modelo de análise do perfil cultural das organizações, tendo como variáveis do modelo, dentre outros, os valores e o poder organizacional.

Valores organizacionais são definidos por Tamayo, Mendes e Paz (2001) "como princípios ou crenças, organizados hierarquicamente, relativos a estados de existência ou a modelos de comportamentos desejáveis que orientam a vida da 
empresa e estão ao serviço de interesses individuais, coletivos ou mistos". Os valores são abordados em três dimensões que representam um contínuo: a relação indivíduo-grupo, pelo eixo de autonomia vs. conservação; a relação estrutural, pelo do eixo hierarquia vs. estrutura igualitária; a relação do meio ambiente social e natural, pelo do eixo harmonia vs. domínio.

Os valores de conservação enfatizam na organização a manutenção do statu quo e a interdição de comportamentos que perturbem as normas e as tradições, enquanto os de autonomia estão relacionados à criatividade e responsabilidade individual, à testagem de novas soluções e novas formas de pensar, agir e executar o trabalho. Valores de hierarquia enfatizam hierarquia e status como forma de garantir o cumprimento da missão organizacional, enfatizando autoridade, fiscalização e supervisão, enquanto os de estrutura igualitária expressam justiça social, igualdade e responsabilidade. Valores de domínio, que caracterizam a relação organização-ambiente, retratam a exploração do meio ambiente e o domínio sobre o mercado, com a imposição de produtos e imagem, enquanto os de harmonia retratam respeito à natureza e bom contato com outras organizações.

Para resolver a questão do grau de congruência ou de envolvimento entre os valores dos indivíduos e das organizações, Tamayo e Borges (2000) estabelecem o coeficiente de satisfação com as prioridades axiológicas da organização, que é obtido por meio da avaliação dos valores no nível do que é real (o que existe na organização) e do que é desejado ou esperado pelos seus membros.

Para abordagem do fenômeno do poder e da política, foi selecionada a teoria do poder organizacional de Mintzberg (1983), que afirma que mudança organizacional consiste na alteração de uma configuração para outra configuração, possibilitada pela ação política dos jogadores que confrontam o sistema de influência legítimo e promovem um realinhamento do poder, de maneira imprevisível, instalando a arena política na organização. A arena política é antecessora de mudança nas características fundamentais na organização. Há tempo para coerência e estabilidade e tempo para mudar: descrevendo períodos de estabilidade relativa dentro em estado organizacional, interrompidos por saltos ocasionais, e mesmo enormes, para novos estados. Esses estados sucessivos de configuração e períodos de transformação podem ordenar-se ao longo do tempo em seqüências padronizadas, descrevendo ciclos de vida das organizações. Para ele as mudanças nas organizações seriam um quantum: a mudança quântica significa mudança de muitos elementos ao mesmo tempo, em comparação com a mudança gradativa um elemento por vez.

Mintzberg propõe seis configurações de poder organizacional que retratam características organizacionais presentes nesses estados. As seis configurações 
propostas são: autocracia, arena política, meritocracia, missionária, instrumento e sistema fechado. Em todas as configurações, há uma descrição dos atores que controlam as decisões organizacionais.

$\mathrm{Na}$ autocracia, o poder é concentrado no mais alto chefe da organização, líder poderoso, que define e maximiza as metas que devem ser perseguidas. $\mathrm{Na}$ configuração instrumento, a organização serve de instrumento para o alcance dos objetivos claramente estabelecidos por um indivíduo ou um grupo, que são os influenciadores dominantes e que estão fora da organização. O grande influenciador na configuração missionária é a ideologia, que mantém a coalizão externa passiva. Centrada numa missão que domina toda a atividade organizacional, a organização favorece uma forte identificação dos seus membros com as metas e os objetivos ideológicos. Na meritocracia, por sua vez, os especialistas são o coração do sistema e têm o poder com base nas habilidades e no domínio de conhecimento e constituem os mais fortes influenciadores internos.

No sistema autônomo (originalmente denominado pelo autor de sistema fechado), quem decide são os próprios membros da organização, principalmente seus administradores que, para fazer o controle interno, usam de padrões burocráticos (em menor proporção que na configuração instrumento), trabalham com sistema de metas claramente operacionalizado, sem imposição externa. Finalmente, a configuração arena política é típica da organização em crise. Nesta condição, há aumento significativo da atividade política, uma vez que ocorre diminuição das forças de integração. Os sistemas de autoridade e ideológico são fracos e o conflito predomina, uma vez que todos perseguem seus objetivos individuais.

Assim, as teorias do poder nas organizações fornecem os indicadores para avaliação da mudança organizacional: o primeiro diz respeito a um padrão de características organizacionais, designadas pelas configurações de Mintzberg, que constituem o próprio conteúdo da mudança organizacional; o segundo se refere a um elemento precipitador da mudança, que seria a existência de coalizões de poder que patrocinam a mudança da organização e nela investem, realizando jogos políticos para efetivar seus desejos e suas necessidades.

Como foi visto até o momento, os fatores listados podem funcionar como conteúdo de mudança, desde que sejam alvo dos programas de mudança planejada. A existência da mudança organizacional, segundo Greenwood e Hinnings (1996), também depende do grau em que a organização consegue mobilizar recursos internos para promovê-la. Os fatores que habilitam para a mudança são dependência de recursos externos para sobreviver e capacidade de ação na dinâmica intraorganizacional. $\mathrm{O}$ conceito de capacidade organizacional para a mudança está relacionado à existência de condições ou características organizacionais, ou dos membros, que são positivamente relacionados à 
implantação do programa de mudanças, ou talvez ainda funcionem como facilitadores da implantação desse programa.

A partir do trabalho de Fisher (2002), os fatores que foram listados como facilitadores da mudança organizacional foram os seguintes: trabalho em grupo, envolvendo unidades e pessoas; burocracia e lentidão organizacionais; direção, flexibilidade e confiança na atuação gerencial; coalizões políticas de apoio à mudança; fluxo de informação abrangente, rápido e preciso; estratégia, refletindo as demandas do ambiente externo; turbulência no ambiente externo; autonomia das unidades e pessoas.

Além desses fatores relacionados anteriormente, Damanpour (1991) aponta que as atitudes dos gerentes em face da mudança determinam a participação dos empregados e o sucesso da implantação do programa de mudanças, o que indica que o processo cognitivo dos indivíduos é determinante no que diz respeito à mudança. Ademais, muitos programas de mudança nas organizações têm seu fracasso atribuído às resistências dos indivíduos (Bovey \& Hede, 2001). Esse argumento somente justifica a análise do processo cognitivo dos indivíduos como componente da mudança organizacional. Neiva, Ros e Paz (2003) apresentam um trabalho em que atitudes de ceticismo, temor e aceitação são apresentadas pelos membros da organização em momentos de mudança.

A partir dessas considerações da literatura, esta pesquisa apresentou basicamente três objetivos:

. Investigar se características organizacionais, levantadas em dois momentos, sofreram alterações após a realização de intervenções na organização.

- Avaliar a existência de características organizacionais que têm sido apontadas pela literatura como facilitadoras dos processos de mudança organizacional.

. Verificar em que medida os servidores da organização percebem que ocorreram as mudanças apontadas como necessárias por entrevistas e documentos produzidos pela organização em momentos anteriores.

\section{Metodologia}

A pesquisa foi desenvolvida em dois momentos diferenciados que seguem esta seqüência cronológica:

. Em 1999 foram investigadas as características organizacionais anteriores a intervenções realizadas na organização. 
. Em 2000 foram levantadas as demandas de mudança por entrevistas e análise de documentos que serviram de base para construção do instrumento de percepção de mudanças individuais e organizacionais.

. Em 2001/2002 foram realizadas intervenções na organização que incluíram processo de planejamento estratégico na organização e organização do trabalho por projetos e envolvendo equipes.

. Em 2003 foram investigadas as características organizações mensuradas em 1999, assim como as atitudes dos indivíduos em relação à mudança, à capacidade organizacional em relação à mudança e às mudanças individuais e organizacionais percebidas.

\section{Instrumentos}

Foram utilizados como instrumentos de pesquisa cinco escalas validadas psicometricamente, aplicadas por meio eletrônico.

\section{a) Configurações de Poder Organizacionais e Valores Organizacionais}

Instrumentos aplicados em 1999 e em 2003 na organização, com o objetivo de levantar as características organizacionais em dois momentos.

A esses instrumentos, na coleta de 2003, foram acrescentados os instrumentos de atitudes em face da mudança organizacional, da capacidade organizacional para mudança e da percepção de mudança no nível individual e organizacional.

\section{b) Atitudes em Face da Mudança}

Para o presente estudo, foi construída uma escala de atitudes perante a mudança, que as autoras validaram para a pesquisa. A escala foi validada com uma estrutura de três fatores, envolvendo as atitudes de aceitação (um fator) e de oposição (dois fatores: temor e ceticismo) às mudanças organizacionais. Tal escala foi construída a partir de entrevistas com profissionais de recursos humanos sobre o processo de mudança organizacional e as reações dos indivíduos ao processo.

\section{c) Capacidade Organizacional ou Recursos Organizacionais que Facilitam a Mudança}

A partir do trabalho de Fisher (2002), as autoras desta pesquisa reformularam 
o instrumento. Foram construídas duas escalas de avaliação da capacidade organizacional para mudanças que mensuram os seguintes fatores:

- Trabalho em grupo, envolvendo unidades e pessoas.

. Burocracia e lentidão organizacionais.

. Direção, flexibilidade e confiança na atuação gerencial.

- Coalizões políticas de apoio à mudança.

. Fluxo de informação abrangente, rápido e preciso.

. Estratégia que reflete as demandas do ambiente externo.

. Turbulência no ambiente externo.

. Autonomia das unidades e das pessoas.

\section{d) Instrumento de Percepção de Mudanças Individuais e Organizacionais}

O instrumento de percepção de mudanças individuais e organizacionais foi construído a partir da análise de documentos e entrevistas com funcionários da organização. Partindo de entrevistas semi-estruturadas e de análise de documentos, foram investigadas as demandas de mudança apontadas pelos atores organizacionais que serviram de base para o planejamento das intervenções para a mudança. Das categorias encontradas na análise de conteúdo e na análise dos documentos, foram construídos itens para o instrumento de percepção de mudanças.

$\mathrm{O}$ instrumento de percepção de mudança individual avalia que seu comportamento mudou em relação à organização e à unidade de trabalho. $\mathrm{O}$ primeiro fator, com dez itens, alfa de cronbach de 0.85 , engloba os itens que avaliam a percepção de mudança comportamental em relação à organização com um todo. $\mathrm{O}$ segundo fator, com doze itens, alfa de cronbach de 0.80 , engloba os itens que avaliam a percepção de mudança comportamental em relação à unidade de trabalho do respondente. Este fator avalia se o indivíduo percebe o que mudou na sua participação na equipe de trabalho, no seu conhecimento das metas da equipe e na autonomia para realização do trabalho.

Para analisar os dados de percepção de mudança organizacional, foram realizadas análises de dimensão do instrumento de percepção de mudança comportamental e organizacional. As dimensões foram definidas pelos pesquisadores a partir da análise do conteúdo dos itens. Além da análise do 
conteúdo dos itens, foi também extraído o alfa de cronbach das dimensões para verificar o grau de precisão delas. A primeira dimensão aborda a ênfase na busca de resultados e alcance de metas da organização e de seus grupos; a segunda dimensão retrata a percepção de horizontalidade e aproximação dos diversos grupos que compõem a organização; a busca por desenvolvimento dos servidores e trabalho de acordo com a competência técnica é retratada pela terceira dimensão; a participação dos servidores nas equipes de trabalho e nas decisões da organização descreve o conteúdo da dimensão quatro; a dimensão cinco retrata a percepção de que os servidores estão sendo valorizados e de que há preocupação com o seu bem-estar; a última dimensão, por sua vez, aborda a imagem externa que a organização tem desenvolvido, bem como sua busca por transparência de ações.

\section{Procedimentos}

A aplicação dos instrumentos foi realizada por meio de um site da Internet, atrelado a um banco de dados, em que o indivíduo respondia às questões e estas eram enviadas e armazenadas no banco. Os instrumentos ficaram disponíveis aos funcionários da organização pelo período de trinta dias Os funcionários receberam correspondências que incentivavam a participação na pesquisa, além de repetir informações sobre como preencher formulários do site.

A organização estudada é uma entidade pública brasileira, com certa autonomia administrativa, destinada a fiscalizar a aplicação dos recursos públicos. Sede no Distrito Federal.

As intervenções realizadas foram: alterações na estrutura organizacional; planejamento e reestruturação do trabalho realizado; criação e aprovação de novo plano de carreira e reformulação das formas de atribuição de recompensas; criação de programas de especialização e investimento em treinamentos; implantação do programa de avaliação de desempenho por resultados e comportamentos; atuação dos componentes organizacionais, com base em projetos com equipes específicas designadas; programa de desenvolvimento de líderes e equipes.

\section{Amostra}

Na primeira aplicação dos instrumentos, 949 sujeitos responderam ao instrumento de configurações de poder e de valores organizacionais. Os instrumentos da segunda aplicação do estudo foram utilizados no mesmo universo de onde se extraiu a primeira amostra do estudo. No total, foram respondidos 456 
questionários, que representam 21,75\% dos 2100 funcionários da organização. Dos funcionários lotados nos Estados, 22,8\% participaram da pesquisa. Apesar da diferença numérica, as características da amostra em termos de dados demográficos foram mantidas. Quanto à participação na pesquisa anterior, $56,1 \%$ tinham feito parte dela, enquanto que $43,9 \%$ não participaram.

\section{Resultados}

A seguir serão apresentados os resultados das análises das variáveis indicadoras de características organizacionais, considerando separadamente os dois momentos de coleta de dados, 1999 e 2003, e comparando os resultados obtidos.

\section{As Configurações de Poder}

Em 1999, a configuração de poder que apresentou maior média na organização foi a configuração autocracia, seguida pela configuração arena política, conforme mostra a Tabela 1, ambas apresentando médias acima do ponto médio da escala (no caso 2, numa escala de 0 a 4 pontos). É importante ressaltar que foi realizado um teste de diferença entre as médias apresentadas em cada configuração. As médias das configurações autocracia e arena política mostram-se estatisticamente diferentes entre si e apresentam diferença estatística quando comparadas às médias das demais configurações.

Assim, considerando-se os resultados, a organização apresentava, em 1999, a configuração autocracia, estando o poder centrado nos mais altos chefes da organização. A configuração arena política se apresentava como possibilidade de instalação de crise na organização.

\section{Tabela 1: Configurações de Poder Identificadas na Organização em 1999}

\begin{tabular}{lcc}
\hline Configuração & Média & Desvio-padrão \\
\hline Autocracia & 2,69 & 0,66 \\
Arena Política & 2,06 & 0,86 \\
Meritocracia & 1,98 & 0,60 \\
Missionária & 1,89 & 0,62 \\
Sistema Fechado & 1,88 & 0,62 \\
Instrumento & 1,84 & 0,73 \\
\hline $\mathrm{N}=949$ & &
\end{tabular}


Na segunda aplicação, Tabela 2, a média para a configuração autocracia continuou praticamente a mesma, com pequena diminuição no desvio-padrão. A configuração arena política, por sua vez, sofreu grande queda numérica, tornando-se a configuração menos presente no grupo de pessoas da amostra. As médias das configurações sistema autônomo e missionária (configurações mais estáveis) obtiveram considerável aumento na percepção dos respondentes.

Tabela 2: Configurações de Poder Presentes na Organização em 2003

\begin{tabular}{ccc}
\hline Configuração & Média & DP \\
\hline Autocracia & 2,59 & 0,61 \\
Sistema Autônomo & 2,20 & 0,54 \\
Missionária & 2,01 & 0,49 \\
Meritocracia & 1,72 & 0,51 \\
Instrumento & 1,56 & 0,51 \\
Arena Política & 1,41 & 0,53 \\
\hline
\end{tabular}

$\mathrm{N}=454$

\section{Prioridades Axiológicas}

Os resultados sobre a percepção dos valores organizacionais reais indicaram que os pólos hierarquia e conservação eram mais característicos da organização em 1999 (Tabela 3) e assim permaneceram em 2003, Tabela 4, com pequena inversão de ordem. A hierarquia era predominante em 1999 e aparece em segundo lugar em 2003.

Quanto aos valores organizacionais reais, a segunda aplicação aponta valores de conservação, hierarquia e harmonia como os mais característicos da organização no momento atual, segundo a percepção dos respondentes. Esses dados estão presentes nas Tabelas 3 e 4.

\section{Tabela 3: Pólos dos Valores Organizacionais Reais Encontrados em 1999}

\begin{tabular}{clcc}
\hline Níveis & Pólos dos Valores Organizacionais Reais & Média & Desvio-padrão \\
\hline 1 & Hierarquia & 3,73 & 0,98 \\
2 & Conservação & 3,56 & 1,07 \\
3 & Autonomia & 2,95 & 1,21 \\
& Harmonia & 2,92 & 1,29 \\
4 & Domínio & 2,60 & 1,31 \\
& Igualitarismo & 2,59 & 1,27 \\
\hline
\end{tabular}


Tabela 4: Prioridades Axiológicas Presentes na Organização em 2003

\begin{tabular}{cccc}
\hline Níveis & Valores & Média & DP \\
\hline 1 & Conservação & 4,31 & 0,97 \\
2 & Hierarquia & 3,96 & 0,80 \\
& Harmonia & 3,83 & 1,12 \\
3 & Autonomia & 3,78 & 0,94 \\
& Igualitarismo & 3,69 & 0,96 \\
4 & Domínio & 3,60 & 0,97 \\
\hline
\end{tabular}

$\mathrm{N}=456$

Foi realizado um teste de diferença de médias, para verificar se os pólos axiológicos que apresentavam maior média eram realmente aqueles que mais caracterizavam a organização. No que diz respeito à percepção das prioridades axiológicas em nível real, foram encontrados quatro níveis hierárquicos, estatisticamente diferentes entre si, nos dois momentos investigados. Há pequenas inversões de ordem nos pólos apresentados, mas a estrutura das prioridades permanece basicamente a mesma. No primeiro e no segundo níveis situam-se os pólos hierarquia e conservadorismo como sendo o conjunto de valores mais praticados na instituição.

No terceiro nível estão autonomia e harmonia, cujos valores são priorizados por organizações que percebem o empregado como entidade autônoma habilitada para perseguir seus próprios interesses e fixar suas metas em harmonia com o ambiente externo e, no quarto nível, domínio e igualitarismo, características de organizações que buscam sucesso, predomínio sobre outras (desejo nítido de impor seus produtos e imagem), bem como valores que expressam preocupação com a igualdade entre membros da organização em geral.

É importante enfatizar que houve considerável diminuição no desvio típico dos valores organizacionais percebidos como orientadores da organização em 2003, o que retrata mais coesão na percepção dos respondentes em relação aos resultados de 1999.

Os valores organizacionais desejados em 1999 são os valores do pólo autonomia e igualitarismo. Com uma inversão de ordem, esses valores permanecem como os mais desejados em 2003, conforme mostram as Tabelas 5 e 6. Os valores organizacionais desejados são os valores do pólo oposto aos valores reais percebidos. 


\section{Tabela 5: Pólos dos Valores Organizacionais Desejados da Organização em 1999}

\begin{tabular}{clcc}
\hline Níveis & Pólos dos Valores Organizacionais Desejados & Média & DP \\
\hline 1 & Autonomia & 5,03 & 0,73 \\
2 & Estrutura igualitária & 4,83 & 0,81 \\
3 & Harmonia & 4,60 & 1,04 \\
& Conservação & 4,53 & 0,87 \\
& Domínio & 4,30 & 1,26 \\
& Hierarquia & 4,25 & 0,92 \\
\hline $\mathrm{N}=944$ & &
\end{tabular}

Tabela 6: Pólos dos Valores Organizacionais Desejados da Organização em 2003

\begin{tabular}{ccccc}
\hline Níveis & Pólos dos Valores Organizacionais Desejados & N & Média & DP \\
\hline \multirow{3}{*}{1} & Igualitarismo & 452 & 4,38 & 1,03 \\
& Autonomia & 452 & 4,35 & 0,95 \\
2 & Conservação & 452 & 4,30 & 0,99 \\
3 & Harmonia & 448 & 4,25 & 1,08 \\
& Domínio & 452 & 3,93 & 0,92 \\
& Hierarquia & 452 & 3,74 & 0,91 \\
\hline
\end{tabular}

$\mathrm{N}=452$

Para a percepção das prioridades axiológicas desejadas, também foram observados quatro níveis de importância em 1999 (Tabela 5). Na parte superior da hierarquia axiológica (nível 1) encontram-se os valores de autonomia, cuja meta motivacional é a procura de caminhos novos para a organização. No nível 2 , os valores de estrutura igualitária, no nível 3 , os valores de harmonia, conservação e domínio, e no quarto nível, a hierarquia.

Em 2003, Tabela 6, observaram-se apenas três níveis de prioridades axiológicas: no primeiro nível, situam-se os valores de igualitarismo e autonomia; no segundo nível, encontram-se os valores de conservação e harmonia; e no terceiro nível, estão os valores dos pólos domínio e hierarquia.

O grau de satisfação com as prioridades axiológicas na organização, Tabelas 7 e 8 , é fornecido pela diferença entre a importância dada pelos servidores aos valores organizacionais desejados e os valores organizacionais reais. A partir dessas diferenças, são obtidas as médias para o grau de insatisfação em relação a cada um dos pólos de valores organizacionais. 


\section{Tabela 7: Grau de Satisfação com as Prioridades Axiológicas da Organização em 1999}

\begin{tabular}{lccc}
\hline Pólos dos Valores Organizacionais & N & Média & Desvio-padrão \\
\hline Igualitarismo & 945 & 2,27 & 1,43 \\
Autonomia & 945 & 2,13 & 1,35 \\
Domínio & 940 & 1,73 & 1,36 \\
Harmonia & 949 & 1,73 & 1,31 \\
Conservação & 948 & 0,99 & 1,19 \\
Hierarquia & 947 & 0,54 & 1,21 \\
\hline
\end{tabular}

Tabela 8: Grau de Satisfação com os Valores Organizacionais da Organização em 2003

\begin{tabular}{cccc}
\hline Pólos dos Valores Organizacionais & N & Média & DP \\
\hline Igualitarismo & 452 & 0,69 & 1,39 \\
Autonomia & 452 & 0,47 & 1,33 \\
Harmonia & 434 & 0,41 & 1,51 \\
Domínio & 452 & 0,33 & 1,27 \\
Conservação & 452 & 0,13 & 1,32 \\
Hierarquia & 452 & $-0,12$ & 1,20 \\
\hline
\end{tabular}

Em 1999, os menores graus de insatisfação com as prioridades axiológicas apresentaram-se nos pólos da hierarquia e da conservação, respectivamente, ou seja, os sujeitos da pesquisa mostraram-se menos insatisfeitos com as prioridades axiológicas, que eram as mais características da instituição. Os maiores graus de insatisfação situaram-se no nível dos pólos estrutura igualitária e autonomia que, por sua vez, eram aqueles mais desejados pelos componentes da organização e, na percepção dos servidores, são os menos praticados na organização atualmente. As informações sobre o grau de insatisfação com as prioridades axiológicas da organização são fornecidos pela Tabela 7 .

Por meio dos dados encontrados em 2003, pode-se detectar que o grau de insatisfação com os valores organizacionais diminuiu bastante para a amostra. Os respondentes continuaram insatisfeitos com os pólos de valores igualitarismo e autonomia, desejando que esses pólos estejam mais presentes na organização. O pólo de valores organizacionais e hierarquia continua sendo o menos desejado pelos respondentes, mas apresentou, em 2003, um grau de insatisfação que não estava presente na aplicação anterior (pouco desejado, muito presente). Outro aspecto importante diz respeito à troca de posição entre os pólos harmonia e domínio, o que indica um desejo atual de maior harmonia com as organizações que coexistem no mesmo ambiente externo, conforme mostra a Tabela 8.

Essa insatisfação com os valores organizacionais sofreu considerável decréscimo em 2003, permanecendo em níveis praticamente inexistentes. Os valores de desvio- 
padrão de 2003 aumentaram, o que pode indicar que a insatisfação com valores pode permanecer apenas em alguns grupos na organização.

\section{Atitudes em Face da Mudança}

Avaliada somente em 2003, as atitudes em face da mudança apresentam resultados importantes, que podem ser comparados aos resultados das aplicações anteriores. No que diz respeito a atitudes em face da mudança, os respondentes ressaltam bem a aceitação e muito temor em relação às mudanças organizacionais. A ocorrência de ceticismo é menos enfatizada pelos respondentes.

\section{Tabela 9: Atitudes em Face da Mudança Organizacional Presentes em 2003}

\begin{tabular}{cccc}
\hline Atitude & N & Média & DP \\
\hline Aceitação & 454 & 2,37 & 0,49 \\
Temores & 456 & 2,29 & 0,55 \\
Ceticismo & 456 & 1,91 & 0,67 \\
\hline
\end{tabular}

Foi realizado um teste de diferença entre as médias das três atitudes em relação à mudança que indicou não existir diferença entre as atitudes de aceitação e temor da mudança.

\section{Capacidade Organizacional para a Mudança}

A organização parece estar vinculada a uma realidade que pouco facilita a introdução de mudanças, uma vez que todas as médias de capacidade são bastante baixas, de acordo com os dados da Tabela 10 .

Tabela 10: Características Organizacionais de Capacidade para Mudança em 2003

\begin{tabular}{cccc}
\hline Fatores & N & Média & DP \\
\hline Trabalho em grupo envolvendo unidades e pessoas & 456 & 2,25 & 0,55 \\
Burocracia & 456 & 2,17 & 0,49 \\
Direção, flexibilidade e confiança na atuação gerencial & 456 & 2,09 & 0,53 \\
Coalizões políticas de apoio à mudança & 456 & 1,98 & 0,44 \\
Fluxo de informação abrangente, rápido e preciso & 456 & 1,93 & 0,66 \\
Estratégia refletindo às demandas do ambiente externo & 452 & 1,88 & 0,66 \\
Turbulência no ambiente externo & 456 & 1,86 & 0,54 \\
Autonomia das unidades e pessoas & 447 & 1,59 & 0,54 \\
\hline
\end{tabular}


Considerando que a organização possui baixa capacidade organizacional para mudança, alguns fatores foram relacionados como aqueles que são mais promissores no funcionamento organizacional. Entre eles, a presença de trabalho em grupo e a autonomia, a presença de comportamentos dos gerentes que promovam a autonomia, o trabalho em grupo e a participação da equipe, além da existência de um processo de comunicação ágil, eficaz e amplo, foram os maiores índices apresentados nas respostas ao questionário. Parece que, apesar de ainda ser bastante limitada, a reformulação na área de tecnologia da organização e a implantação da gerência por projetos, tornou um pouco menos problemáticos esses aspectos da organização.

Esses resultados salientados até o momento parecem refletir alguns pontos sobre as características dessa organização durante o período de quatro anos. Como características principais, a organização apresenta: a configuração autocracia, nas duas aplicações do instrumento; os valores de conservação e hierarquia, que também permaneceram como orientadores da vida organizacional durante esses anos; as atitudes dos indivíduos em face da mudança organizacional são de aceitação e temor. A capacidade organizacional para a mudança é baixa, mesmo tendo sido implantadas algumas intervenções.

\section{Percepção de Mudança Organizacional e Individual}

Quando considerados os fatores dos instrumentos, a percepção de mudança individual aparece muito mais intensa do que a percepção da mudança organizacional, de acordo com a Tabela 11. Entre esses dois comportamentos, os relacionados à organização aparecem mais alterados que os relacionados à unidade de trabalho.

Em relação à organização, os indivíduos percebem que a imagem externa da organização sofreu uma considerável melhoria, enquanto a horizontalidade dela e a participação do servidor mudaram com menos ênfase, de acordo com as Tabelas 11 e 12.

Tabela 11: Percepção de Mudança Individual dos Respondentes

\begin{tabular}{cccc}
\hline Mudanças individuais & N & Média & DP \\
\hline Comportamento em relação à organização & 452 & 4,04 & 0,73 \\
Comportamento em relação à unidade & 450 & 3,92 & 0,83 \\
\hline
\end{tabular}


Tabela 12: Percepção de Mudança Organizacional

\begin{tabular}{cccc}
\hline Mudanças organizacionais & N & Média & DP \\
\hline Imagem Externa & 433 & 3,83 & 0,80 \\
Resultados Organizacionais & 433 & 3,77 & 0,65 \\
Competência & 433 & 3,62 & 0,65 \\
Bem-estar dos servidores & 433 & 3,56 & 0,72 \\
Participação dos servidores & 433 & 3,43 & 0,91 \\
Horizontalidade & 433 & 3,22 & 0,65 \\
\hline
\end{tabular}

\section{Discussão e Conclusões}

A discussão do texto se concentra em dois aspectos: se houve mudança nesses quatro anos de intervenção na organização e quais são as condições da organização hoje para implantar algum processo de mudança.

Em relação às características organizacionais, a grande mudança a ser ressaltada foi a alteração na configuração de poder arena política, o que indica uma calmaria nos jogos políticos e nas movimentações de apoio a mudanças na organização. A diminuição da configuração arena política indica acomodação dos grupos que incentivavam as mudanças em um momento anterior, pois atualmente há inexistência de coalizões indicada pelos resultados da capacidade organizacional para a mudança.

Em 1999, a configuração Arena Política ganhava corpo na organização pesquisada, possivelmente, em virtude de forças de grupos ou mudanças no ambiente externo que a pressionavam, e estimulavam a instabilidade na organização. A arena política caracteriza-se por se instalar em momentos de crise e pode resultar em mudança de configuração da organização ou manutenção da configuração anterior, com mudanças menos profundas no funcionamento organizacional. A instalação da arena política implica alternâncias no poder, presença mais enfática de jogos políticos e grupos lutando para impor suas diretrizes na organização, o que faz parte do processo de desenvolvimento organizacional.

A diminuição da configuração arena política e o aumento das configurações missionária e sistema fechado, no segundo momento, parece indicar uma acomodação no ambiente interno da organização. Essa calmaria também se confirma pelo fato do grau de insatisfação com os valores praticamente não existir mais na organização. Os indivíduos demonstram menos insatisfação com os valores organizacionais atuais. 
A intensidade do anseio pela ocorrência de tais valores (autonomia e igualitarismo) sofreu considerável decréscimo em 2003, o que pode indicar também uma acomodação da realidade organizacional, que parece não mais apresentar demandas de mudança consideráveis. Os valores desejados, que não fazem parte da realidade organizacional, constituem demandas de mudança; entretanto estes não são respaldados pela insatisfação com o que existe, e sim pelo que não se possui. Em 2003, esse desejo com o que não existe parece ter sido extinto. Somente os valores de hierarquia são objeto, atualmente, de pequena insatisfação com o que existe na organização. Isso sim pode vir a ser uma demanda de mudança que reflete falta de envolvimento com os valores organizacionais (Greenwood \& Hinnings, 1996).

Segundo Greenwood e Hinnings (1996), insatisfação de interesses e envolvimento com valores organizacionais são precipitadores de mudança nas organizações. A satisfação com valores organizacionais aborda, por analogia, envolvimento com valores organizacionais, o que indica um fator de precipitação de mudanças. Desejo por uma realidade diferente da atual e insatisfação com a atual são, por analogia, demanda de mudança ou possibilidade de mudança. Segundo os dados de 1999, a insatisfação com as prioridades axiológicas revelavam uma demanda de mudança cultural, ou seja, um potencial para mudanças, fundamentado principalmente naquilo que era desejado para a vida organizacional e que não fazia parte dela. A vida organizacional era percebida como orientada pela presença de níveis hierárquicos na organização, pela manutenção de tradições, normas e pelo amplo exercício da autoridade entre os indivíduos.

Os resultados indicam que não houve mudança cultural na organização, pois as características de organização hierarquizada, com autoritarismo de um grupo preponderante e divisão de grupos por importância, permanecem as mesmas.

No que diz respeito às características organizacionais que facilitam as mudanças, é importante ressaltar que todas as características facilitadoras se encontram com médias baixas na organização pesquisada, o que indica pouca possibilidade de implantação de programas de mudança na organização. As condições para a mudança em termos de capacidade e atitudes não são muito favorecedoras. Por ser uma organização pública da administração direta, com recursos oriundos da União, tal análise é bastante pertinente.

As atitudes dos indivíduos também demonstram um apoio amedrontado aos programas de mudança. Os indivíduos parecem apoiar algo que não retire as vantagens que possuem por trabalhar na instituição.

Ao avaliar a capacidade organizacional para mudança de acordo com a tipologia de Gravenhorst, Werkman e Boonstra (2003), essa realmente seria uma 
organização cínica ou uma organização longing, cujas características organizacionais são avaliadas negativamente. Em ambos os casos, as características organizacionais facilitadoras da mudança são avaliadas negativamente. A diferença das organizações cínicas para as longings diz respeito à avaliação da necessidade de mudança. Atitudes em face da mudança podem ser consideradas indicadores da avaliação da necessidade de mudança. Como existe elevado índice de atitudes negativas, a organização teria potencial maior para uma organização cínica.

Os dados sobre atitudes em face da mudança poderiam ter sofrido mudanças ao longo dos quatro anos, pois uma das possibilidades é que o próprio programa de mudanças atue sobre as características organizacionais e sobre os indivíduos durante o período. Contudo esses dados não foram mensurados anteriormente com as escalas preparadas; então não se pode dizer com certeza que houve manutenção das atitudes durante esses quatro anos.

Uma explicação para a presença limitada de ceticismo (médias abaixo do ponto médio - 1,91, ponto médio igual a 2,0) pode estar no fato de as atitudes negativas perante a mudança serem peculiares a alguns grupos na organização.

Os indivíduos percebem significativa mudança nos seus comportamentos em relação à organização e à unidade de trabalho, mas não conseguem perceber uma alteração significativa na participação dos funcionários nas decisões da organização e da unidade de trabalho. É importante ressaltar que, embora os teóricos (Porras \& Hoffer, 1986; Porras \& Robertson, 1992; Robertson, Robertson, \& Porras, 1993; Robertson, 1994) apontem uma ligação entre comportamentos individuais e mudanças organizacionais, ainda há muito que se pesquisar e teorizar sobre isso. A questão do tempo pode afetar diretamente essa percepção, mas não se pode precisar em que medida algumas ações contribuíram para isso. Pode ser que esse elo entre comportamentos individuais e mudanças organizacionais percebidas ocorra de maneira frouxa e dimensionada pelo tempo.

É importante ressaltar também que a percepção de mudança com base em autorelato pode sofrer do mesmo fenômeno que atinge as auto-avaliações de maneira geral (Neiva, 2000). Os indivíduos costumam ser indulgentes em suas auto-avaliações.

Por fim, os indivíduos percebem que, durante esses quatro anos, houve mudanças da organização quanto à produtividade e à ênfase em resultados, bem como a imagem externa da organização parece haver ficado mais positiva, segundo a percepção dos respondentes do questionário.

A alteração na imagem da organização, percebida pelos membros, pode ter ocorrido em função da ausência de escândalos e reportagens na mídia que 
denegriam a imagem da organização perante a sociedade. Pode ter havido também alteração na imagem da organização em face dos seus clientes primários, funcionários de órgãos governamentais. A alteração nos resultados organizacionais pode ser em função de todo o programa de planejamento realizado na organização no ano de 2002, que estabeleceu metas e novas formas de organizar processos e rotinas de trabalho a eles relacionadas. Além do planejamento da atuação na organização, o processo de avaliação de desempenho que privilegia os resultados do grupo de trabalho pode ter contribuído para esse resultado.

A melhoria na participação dos servidores nas decisões organizacionais, expressa pelos itens de autonomia dos servidores, realização de alianças e trabalho em equipes, parece não ter sido alcançada, apesar de ter sido objeto das intervenções dos programas de desenvolvimento de líderes e equipes e da gerência por projetos. A implantação da gerência por projetos poderia ter apresentado impacto sobre a participação dos servidores nas decisões (na unidade de trabalho e na organização) e na horizontalidade organizacional.

A percepção de melhoria no bem-estar dos servidores pode ser atribuída à reformulação dos programas de recompensas e à aprovação de um novo plano de carreira para os funcionários. Melhoria no desenvolvimento das competências dos servidores e atuação baseada nas especializações dos funcionários parecem ser explicadas pela implantação da gerência de projetos e pelo investimento em treinamentos e especializações para o trabalho.

Retomando o conceito de mudança organizacional relatado aqui, houve alteração nos componentes organizacionais, como imagem, desenvolvimento e atuação baseada nas competências profissionais, além de haver percepção de alteração nos resultados organizacionais, o que apresenta repercussão para o conceito de mudança organizacional adotado. Entretanto, se forem retomadas as demandas de mudança apresentadas anteriormente, as alterações listadas ficam aquém do que foi estipulado. As mudanças parecem ter atingido as características da organização que, segundo Burke e Litwin (1992), constituem alvo de mudanças transacionais ou contínuas (Weick \& Quinn, 1999). Com a comparação das características, apresentadas aqui como características indicadoras da cultura da organização (valores e configurações de poder), não foi possível detectar mudança transformacional.

Um dos fatores que explicam a ausência de mudanças transformacionais pode ser a amplitude das intervenções realizadas, que podem não atingir tal espectro. Apenas o processo de planejamento da atuação organizacional poderia ter atingido uma amplitude estratégica suficientemente capaz de ter tal impacto. As demais intervenções poderiam atingir os componentes de processos de trabalho, práticas gerenciais e estrutura organizacional. Ou ainda, essas intervenções podem ter 
sido um passo para a mudança transformacional que ocorrerá dentro de um período de tempo superior a quatro anos, ao considerar-se que a proposta de atuação estratégica pautada na fiscalização ainda pode permanecer.

\section{Artigo recebido em 10.08.2004. Aprovado em 23.11.2004.}

\section{ReferênCIAS BibliográficAS}

Bennebroek Gravenhorst, B. K.,

Werkman, R.A., \&

Boonstra, J. J. (2003).

The change capacity of organisations: general assessment and five configurations. Applied Psychology: an International Review, 52(1), 83-105.

Bovey, W. H., \&

Hede, A. (2001).

Resistance to organizational change: the role of cognitive and affective processes. Leadership \& Organization Development Journal, 22(8), 372-382.

Burke, W., \&

Litwin, G. (1992).

A causal model of organizational performance and change. Journal of Management, 18(1), 523-545.

Damanpour, F. (1991).

Organizational innovation: a metaanalysis of effects of determinants and moderators. Academy of Management Journal, 34(3), 555-590.

Fisher, H. C. (2002).

Validação de um instrumento de avaliação dos fatores restritivos e propulsores da mudança organizacional. Dissertação de Mestrado, Universidade de Brasília, Brasília, DF.
Greenwood, R. E., \&

Hinnings, C. R. (1996).

Understanding radical organizational change: bringing together the old and the new institutionalism. Academy of Management Review, 21(4), 10221054.

Lima, S. M. V., \&

Bressan, C. L. (2003).

Mudança organizacional: uma introdução. In S. M. V. Lima (Org.). Mudança organizacional: teoria e gestão (pp. 17-61). São Paulo: Editora FGV.

Mintzberg, H. (1983).

Power in and around organizations. Englewood Cliffs, New Cork: Prentice Hall.

Neiva, E. R. (2003).

Metodologia para avaliação da mudança organizacional. In S. M. V. Lima (Org.). Mudança organizacional: teoria e gestão (pp. 191215). São Paulo: Editora FGV.

Neiva, E. R. (2004).

Percepção de mudança organizacional: o papel das atitudes e das características organizacionais. Tese de Doutorado, Universidade de Brasília, DF, Brasil. 
Neiva, E. R.,

Ros, M., \&

Paz, M. G. T. (2004).

Validacion de una escala de actitudes ante el cambio organizacional. Revista de Psicologia Del Trabajo y das Organizaciones, 20(1), 9-30.

Paz, M. G. T., \&

Tamayo, A. (2004).

Perfil cultural das organizações. In A. Tamayo (Ed.). Cultura e saúde nas organizações. Porto Alegre: Artmed.

Porras, J. I., \&

Robertson, P. J. (1992).

Organizational development: theory, practice, research. In M. D. Dunnette, \& L. M. Hough (Eds.). Handbook of organizational psychology (2nd ed., Vol. 3), 719-822. Palo Alto, C.A: Consultant Psychology Press.

Porras, J. I., \&

Hoffer, S. J. (1986).

Common behavior changes in successful organization development efforts. The Journal of Applied Behavioral Science, 22(4), 477-489.

Robertson, P. J.,

Roberts, D., \&

Porras, J. (1993).

Dynamics of planned organizational change: assessing empirical support for a theoretical model. Academy of Management Journal, 36(3), 619-634.
Robertson, P. J. (1994).

The relationship between work setting and employee behavior: a study of a critical linkage in the organizational change process. Journal of Organizational Change and Management, 7(3), 22-43.

Tamayo, A., \&

Borges, L. (2000).

Valores del trabalho e valores de las organizaciones. In M. Ros, \& V. V. Gouveia (Eds.). Psicología social de los valores humanos: desarrolos teóricos, metodológicos y aplicados. Madri: Biblioteca Nueva.

Tamayo, A.,

Mendes, A. M., \&

Paz, M. G. T. (2001).

Inventário de valores organizacionais. Estudos de Psicologia, 5(2), 289-315.

Tienari, J., \&

Tainio, R. (1999).

The myth of flexibility in organizational change. Scandinavian Journal of Management, 15(1), 351384.

Weick, K. E., \&

Quinn, R.E. (1999).

Organizational change and development. Annual Review of Psychology, 50(1), 50, 361-387. 